\title{
Clinical Study \\ Value of Procollagen Type I Aminoterminal Propeptide in Women with Breast Cancer with regard to Metastases
}

\author{
A. Clouth ${ }^{1}$ and G. M. Oremek ${ }^{2}$ \\ ${ }^{1}$ Department of Gynecology, Hospital of the Johann Wolfgang Goethe University, Theodor-Stern-Kai 7 , \\ 60590 Frankfurt, Germany \\ ${ }^{2}$ Department of Laboratory Medicine, Hospital of the Johann Wolfgang Goethe University, Theodor-Stern-Kai 7, \\ 60590 Frankfurt, Germany \\ Correspondence should be addressed to G. M. Oremek, oremek@gmx.net
}

Received 1 June 2011; Revised 6 September 2011; Accepted 7 September 2011

Academic Editor: Louise J. Jones

Copyright (C) 2011 A. Clouth and G. M. Oremek. This is an open access article distributed under the Creative Commons Attribution License, which permits unrestricted use, distribution, and reproduction in any medium, provided the original work is properly cited.

Background. The aim of this study was to show the importance of the bone marker procollagen type 1 aminoterminal propeptide (P1NP) in detecting bone metastases in women suffering from breast cancer. We furthermore investigated to what degree P1NP is correlated to the degree of bone metastases, and if P1NP is increased in patients with metastases other than bone. Patients and Methods. We analyzed 80 serum samples of women (17 premenopausal/63 postmenopausal) with breast cancer. Therefore we used a specific immunoassay "ELECSYS 2010" by Roche Diagnostics. We divided our group of patients with regard to menopausal status, sites of metastases and number of bone metastases. Results. As a result we found higher concentrations of P1NP in women with radiologically confirmed bone metastases (median: $125.75 \mathrm{ng} / \mathrm{mL}$ ) in comparison to the collective without bone involvement (median: $73.61 \mathrm{ng} / \mathrm{mL}$ ). However, both groups showed values above the applied cutoff values of median $27.8 \mathrm{ng} / \mathrm{mL}$ for premenopausal women and median: $37.1 \mathrm{ng} / \mathrm{mL}$ for the postmenopausal group due to the fact that all patients had cancer. Furthermore higher P1NP concentrations were found in women with more than 5 sites of bone metastases (median: $183.9 \mathrm{ng} / \mathrm{mL}$ ) than in patients with only one site of bone metastases (median: $37 \mathrm{ng} / \mathrm{mL}$ ). Also patients with no bone involvement but other sites of metastases showed quite high P1NP concentrations (median: $73.61 \mathrm{ng} / \mathrm{mL}$ ). Conclusion. The marker of bone turnover procollagen type 1 aminoterminal propeptide can be considered as a useful tool for estimating the extent of bone involvement and for the detection of bone metastases. P1NP cannot replace conventional methods for detecting bone metastases such as radiological methods but it can help clarify unclear radiological results. This study does not take into account the change of P1NP concentration during the course of therapy.

\section{Introduction}

Bone mainly consists of two components. There are the cellular elements such as osteoclasts, osteoblasts, and osteocytes, and there is the cellular matrix representing the main component of bone. $90 \%$ of the cellular matrix of bone is collagen tissue; the remaining $10 \%$ are noncollagenous proteins and minerals. Especially collagen type 1 is crucial for the typical structure of bone. Synthesis of mature type 1 collagen is realised by the precursor proteins procollagen and tropocollagen. Mature type 1 collagen is a heterotrimer consisting of two identical a1 chains and one a 2 chain. During collagen synthesis specific proteases remove $\mathrm{N}$ - and C-terminal extensions of the precursor protein procollagen type 1 . These extensions are referred to as the $\mathrm{C}$ - and $\mathrm{N}$-terminal propeptides of procollagen type 1: P1CP and P1NP [1-3].

Bone underlies an ongoing process of reconstruction. The two competing process are bone resorption realised by osteoclasts and matrix formation induced by osteoblasts [1]. For the function of bone it is crucial that these processes are balanced. However, there are diseases interfering with these processes, such as osteoporosis or bone metastases. Therefore certain markers of bone turnover have been detected and investigated in order to facilitate the assessment of bone metabolism. Bone markers representing osteoblast activity and 
therefore bone formation, for instance, are alkaline phosphatase and its bone-specific isoenzyme, osteocalcin, procollagen type 1 carboxyterminal propeptide (P1CP), and procollagen type 1 aminoterminal propeptide (P1NP). Bone markers associated with bone resorption are hydroxyprolin, pyridinium crosslinks, c-telopeptide crosslink of type $1 \mathrm{col}-$ lagen (CTX), and n-telopeptide crosslink of type 1 collagen (NTX).

The aim of our study was to evaluate the clinical usefulness of the bone formation marker procollagen type 1 aminoterminal propeptide (P1NP) in detecting bone metastases in women with histologically confirmed breast cancer and to show to what extent P1NP concentrations correlate with the degree of bone involvement.

\section{Patients and Methods}

In our study we analysed serum samples of eighty women with histologically confirmed breast cancer. All women were treated in the hospital of the Johann Wolfgang Goethe University in Frankfurt. The samples were collected during the years 2005 to 2007 . The women were separated into several groups with regard to their menopausal status, sites of metastases, extent of bone involvement, and hormonal therapy. When serum samples were collected, 17 women were premenopausal, 63 postmenopausal. 62 patients had radiologically confirmed bone metastases (14 premenopausal, 48 postmenopausal). In the group of patients with bone involvement, 52 additionally had metastases in other sites. From all patients, 15 showed no bone involvement at the date of the study. Some of the patients received hormonal treatment but the study did not focus on the treatment because different treatments develop different P1NP values. Also the stage of therapy influences the P1NP concentration.

For the measurement of P1NP serum concentrations we applied the Electrochemiluminescence Immunoassay "ECLIA"/Elecsys 1010 by ROCHE Diagnostics, Mannheim, Germany. This assay is based on a sandwich principle using streptavidin-coated microparticles, biotinylated monoclonal antibodies, and monoclonal anti-P1NP antibodies associated with a ruthenium complex. For the analyses of our data we referred to the cutoff values recommended by the median $27.8 \mathrm{ng} / \mathrm{mL}$ for premenopausal women and median: $37.1 \mathrm{ng} / \mathrm{mL}$ for the postmenopausal group.

All statistical calculations were performed with Microsoft Office Excel 2003 as well as BIAS for Windows.

\section{Results}

In our study P1NP values ranged from $13.99 \mathrm{ng} / \mathrm{mL}$ to $981.6 \mathrm{ng} / \mathrm{mL}$. In terms of our question we found significantly higher P1NP values in patients with proven bone involvement (median: $125.75 \mathrm{ng} / \mathrm{mL}$ ) compared to the control group without bone metastases (median: $73.61 \mathrm{ng} / \mathrm{mL}$ ). Taking into consideration the menopausal status we found for the group of premenopausal women with bone metastases a median P1NP value of $253.65 \mathrm{ng} / \mathrm{mL}$, and for the women without bone involvement the median was $76.07 \mathrm{ng} / \mathrm{mL}$. With respect to the postmenopausal women with skeletal
TABLE 1: P1NP in women with breast cancer without (NMS) and with skeletal metastases (MS).

\begin{tabular}{lcc}
\hline & NMS & MS \\
\hline Number of patients & 18 & 62 \\
Median P1NP & $73.61 \mathrm{ng} / \mathrm{mL}$ & $125.75 \mathrm{ng} / \mathrm{mL}$ \\
Minimum P1NP & $13.99 \mathrm{ng} / \mathrm{mL}$ & $14.7 \mathrm{ng} / \mathrm{mL}$ \\
Maximum P1NP & $243 \mathrm{ng} / \mathrm{mL}$ & $981.6 \mathrm{ng} / \mathrm{mL}$ \\
\hline
\end{tabular}

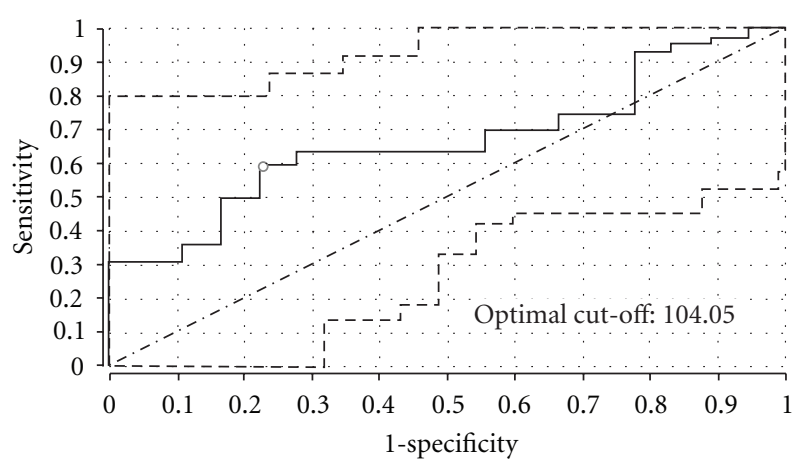

FIgURE 1: ROC analyses for P1NP.

metastases the median P1NP value was $105.6 \mathrm{ng} / \mathrm{mL}$, and without such metastases it was $66.71 \mathrm{ng} / \mathrm{mL}$. These results are represented in Table 1 .

However, all medium values obtained significantly lie above the cutoff values used in this study (premenopausal median: $27.1 \mathrm{ng} / \mathrm{mL}$, postmenopausal median: $37.1 \mathrm{ng} / \mathrm{mL}$ ). The cutoff values applied were recommended by the manufacturer of the immunoassay system [4].

When it comes to specificity and sensitivity we obtained unsatisfactory results when using these cutoff values. The specificity obtained was $22 \%$, and sensitivity reached $87 \%$.

When using ROC analyses the perfect cutoff-point turned out to be $104 \mathrm{ng} / \mathrm{mL}$. The AUC value obtained was 0.66. ROC curve is represented in Figure 1.

The low specificity and sensitivity found stem from the fact that all patients have confirmed cancer. To receive better values it would be necessary to look at the treatment the patient is receiving and look at the change of the P1NP concentration during the course of treatment.

Furthermore we found that P1NP serum concentrations represent the extent of bone involvement. Women with only little bone involvement, that means with less than five sites of skeletal metastases, showed lowest P1NP levels (median: $49.55 \mathrm{ng} / \mathrm{mL}$ ), whereas women with multiple osseous metastases, that means more than five sites, showed quite high values (median: $183.7 \mathrm{ng} / \mathrm{mL}$ ). Results are represented in Table 2 .

The change in minima to be low for the patient with more than 5 sites of bone metastases is most likely due to the fact that the patient has been receiving treatment for a prolonged period.

Furthermore we investigated the effect of metastases other than bone on P1NP serum levels. As a result P1NP concentrations were found to also be elevated in patients only 
TABLE 2: Correlation between P1NP levels and extent of bone metastases.

\begin{tabular}{lcccc}
\hline Number of sites of skeletal metastases & 1 & $>1<5$ & 5 & $>5$ \\
\hline Median: P1NP ng/mL & 37.1 & 50.62 & 52.79 & 183.7 \\
Minimum: P1NP ng/mL & 28.22 & 14.7 & 49.55 & 19.75 \\
Maximum: P1NP ng/mL & 45.89 & 163.5 & 156.0 & 981.6 \\
\hline
\end{tabular}

TABle 3: P1NP serum levels depending on different sites of metastases.

\begin{tabular}{lccc}
\hline Site of metastases & $\begin{array}{c}\text { Exclusively } \\
\text { skeletal }\end{array}$ & $\begin{array}{c}\text { Exclusively } \\
\text { visceral }\end{array}$ & $\begin{array}{c}\text { Skeletal } \\
\text { and visceral }\end{array}$ \\
\hline Median: P1NP l & $52.79 \mathrm{ng} / \mathrm{mL}$ & $73.6 \mathrm{ng} / \mathrm{mL}$ & $162.75 \mathrm{ng} / \mathrm{mL}$ \\
Minimum: P1NP & $14.8 \mathrm{ng} / \mathrm{mL}$ & $16.3 \mathrm{ng} / \mathrm{mL}$ & $22.47 \mathrm{ng} / \mathrm{mL}$ \\
Maximum: P1NP & $561.1 \mathrm{ng} / \mathrm{mL}$ & $243.5 \mathrm{ng} / \mathrm{mL}$ & $981.6 \mathrm{ng} / \mathrm{mL}$ \\
\hline
\end{tabular}

showing extraskeletal metastases. Highest serum P1NP levels were obtained for the group of women with extensive metastases in several sites including bone. Results are represented in Table 3.

\section{Discussion}

At present, bone metastases are detected by imaging techniques such as bone scintigraphy, $\mathrm{X}$-ray photographs, and computed tomography. These methods are quite expensive, time-consuming and involve radiation exposure. Apart from that, bone scintigraphy as a main tool for detecting bone metastases shows high sensitivity but lacks specificity [5]. Therefore it would be interesting to find favourable methods for the early detection and assessment of skeletal metastases. One approach is to identify bone markers either representing bone resorption or bone formation as bone metastases interfere with bone metabolism. Therefore several study groups analysed the effect of skeletal metastases on certain bone markers. De la Piedra et al., for example, compared concentrations of several markers of bone turnover such as P1NP, specific alkaline phosphatase, and procollagen type 1 aminoterminal telopeptide (NTX) in men suffering from prostate carcinoma with and without bone involvement. All investigated bone markers showed significantly higher levels in patients with bone metastases. For P1NP they found a sensitivity as well as specificity of $100 \%$ [6]. A previous study by Diaz-Martin et al. found similar values for P1NP with regard to this question. In their study specificity was $87 \%$; sensitivity reached $100 \%$ [7]. Jung et al. also obtained significantly higher values for P1NP in case of bone involvement in comparison to the control group without bone metastases [8].

In accordance to the studies represented higher P1NP serum concentrations were found in women suffering from breast cancer and bone metastases (median: $125.75 \mathrm{ng} / \mathrm{mL}$ ) in comparison to the group without bone involvement $(73.61 \mathrm{ng} / \mathrm{mL})$. However, using the cutoff values recommended by the producer we obtained unsatisfactory values for sensitivity (87\%) and specificity (22\%). This is due to the fact that all patients had confirmed cancer. Neither the stage of therapy nor the stage of cancer was taken into account in this study.

With respect to the question whether P1NP is useful in assessing the extent of bone involvement Koizumi et al. found that P1NP is a valid marker in representing the degree of bone metastases [9]. Therefore this study supports their findings. In our study we also found the highest P1NP concentrations in case of extensive bone involvement.

As a further result we found elevated P1NP serum levels also in patients with extensive metastases other than bone. These findings might support a study undertaken by Jensen et al. showing that an aggressive cancer disease is correlated to high P1NP levels. In their study, Jensen et al. were able to prove that extensive P1NP levels are associated to an aggressive progression of the disease with a shorter live expectancy than the control group with lower P1NP levels [10].

\section{Conclusions}

The results obtained suggest P1NP are a valid marker in assessing bone involvement in women with breast cancer. Due to lack of sensitivity as well as specificity we cannot recommend to replace conventional methods for detecting bone metastases. However, in the case of unclear radiological results elevated P1NP levels suggest metastases. Yet, P1NP can be seen as a helpful tool for supervising and assessing the development of bone metastases. This study did not take into account the therapy prescribed. As further field of investigation, a study with regards to stage of cancer as well as treatment would further show the usefulness of P1NP as indicator.

\section{References}

[1] M. J. Seibel and M. E. Kraenzlin, "Osteoporose- Moderne Diagnostik. Therapeutische Konsequenzen für Klinik und Praxis," in Interdisziplinäres Osteoporose Symposium (1. IDOS), pp. S13-S17, Basel, Schweiz, Oktober 1995.

[2] K. Von der Mark, Structure, Biosynthesis and Gene Regulation of Collagens in Cartilage and Bone, Dynamics of Bone and Cartilage Metabolism, Academic Press, Orlando, Fla, USA, 1999.

[3] B. Goldberg, M. B. Taubman, and A. Radin, "Procollagen peptidase: its mode of action on the native substrate," Cell, vol. 4, no. 1, pp. 45-50, 1975.

[4] M. Klepzig, H. Sauer-Eppel, D. Jonas, and G. M. Oremek, "Value of procollagen type 1 amino-terminal propeptide in patients with renal cell carcinoma," Anticancer Research, vol. 28, no. 4, pp. 2443-2446, 2008.

[5] D. I. Rosenthal, "Radiologic diagnosis of bone metastases," Cancer, vol. 80, supplement 8, pp. 1595-1607, 1997.

[6] C. De la Piedra, N. A. Castro-Errecaborde, M. L. Traba et al., "Bone remodeling markers in the detection of bone metastases in prostate cancer," Clinica Chimica Acta, vol. 331, no. 1-2, pp. 45-53, 2003.

[7] M. A. Diaz-Martin, M. L. Traba, C. De la Piedra, R. Guerrrero, C. Mendez-Davila, and E. G. De la Pena, "Aminoterminal propetide of the type I collagen and bone alkaline phosphatase in the study of bone metastases assoziated with prostatic carcinoma," Scandinavian Journal of Clinical and Laboratory Investigation, vol. 59, no. 2, pp. 125-132, 1999. 
[8] K. Jung, M. Lein, C. Stephan et al., "Comparison of 10 serum bone turnover markers in prostate carcinoma patients with bone metastatic spread: diagnostic and prognostic implications," International Journal of Cancer, vol. 111, no. 5, pp. 783791, 2004.

[9] M. Koizumi, Y. Yonese, I. Fukui, and E. Ogata, “The serum level of the amino-terminal propeptide of type I procollagen is a sensitive marker for prostate cancer metastasis to bone," British Journal of Urology International, vol. 87, no. 4, pp. 348351, 2001.

[10] B. V. Jensen, J. S. Johansen, T. Skovsgaard, J. Brandt, and B. Teisner, "Extracellular matrix building marked by the N-terminal propeptide of procollagen type I reflect aggressiveness of recurrent breast cancer," International Journal of Cancer, vol. 98, no. 4, pp. 582-589, 2002. 


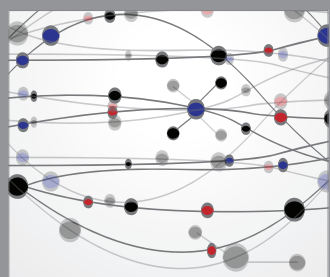

The Scientific World Journal
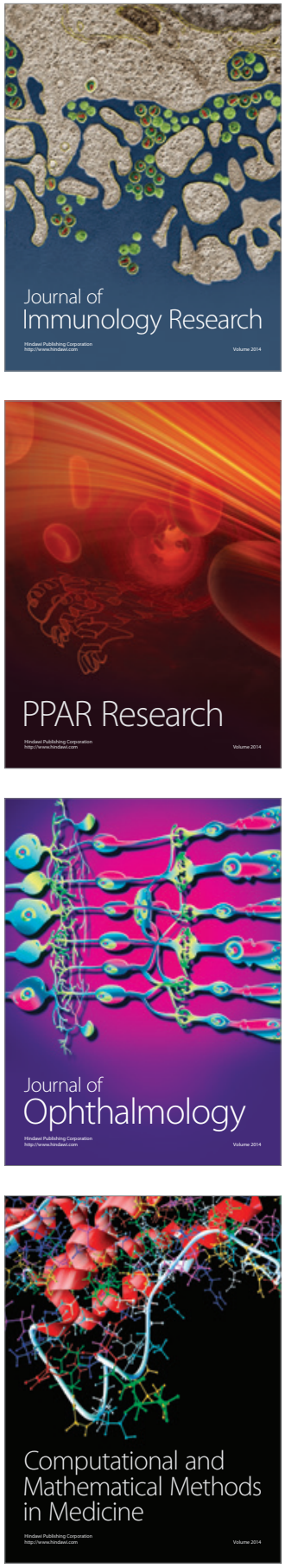

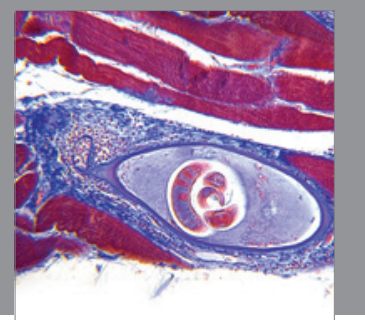

Gastroenterology

Research and Practice
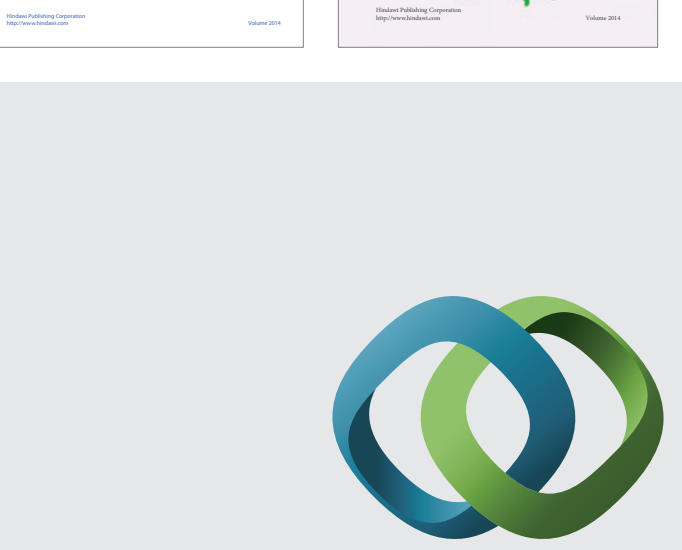

\section{Hindawi}

Submit your manuscripts at

http://www.hindawi.com
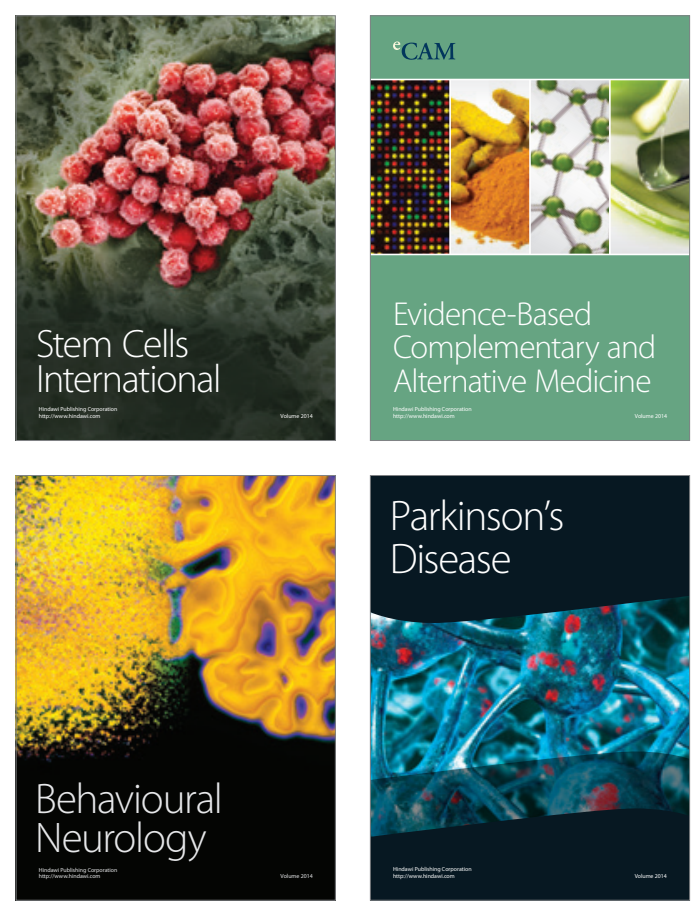

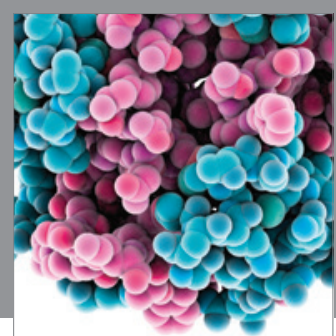

Journal of
Diabetes Research

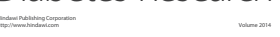

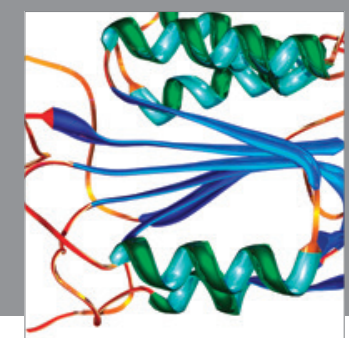

Disease Markers
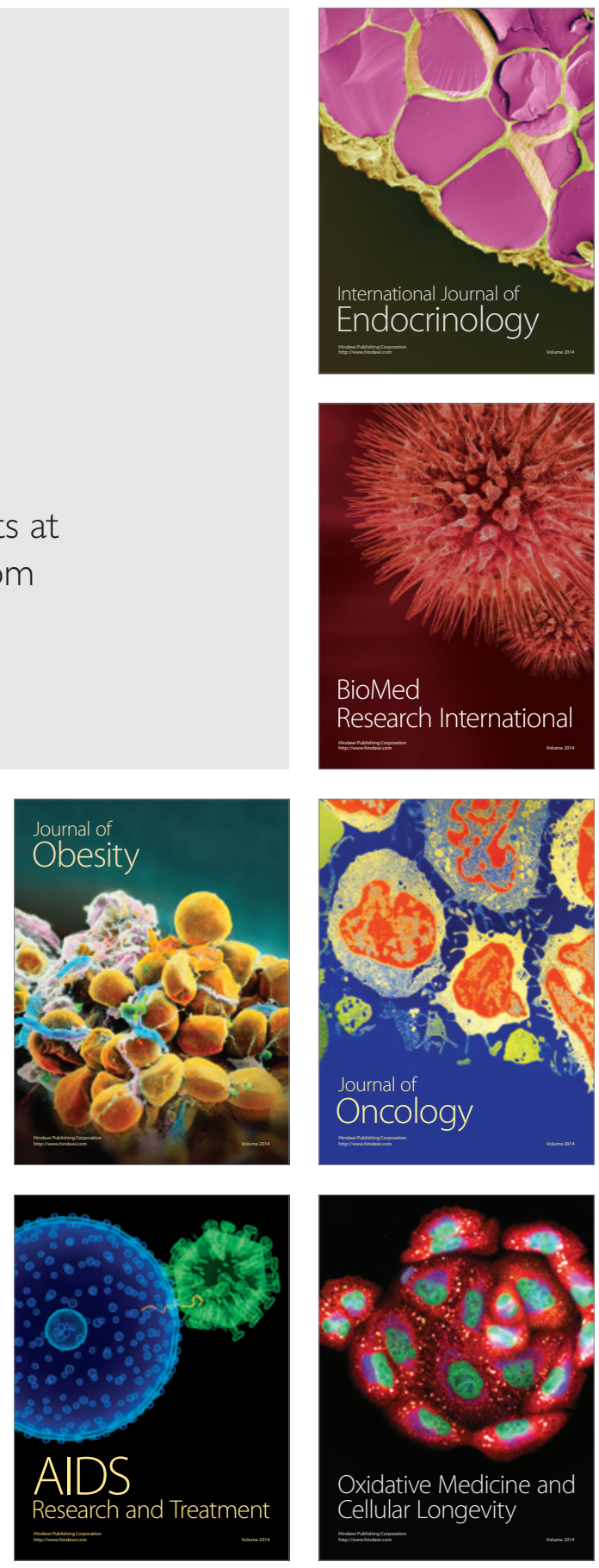